\title{
LATE METASTASIS OF BREAST ADENOCARCINOMA INTO INTERNAL AUDITORY CANAL AND CEREBELLOPONTINE ANGLE
}

\section{Case report}

\author{
Edilson Marques', Almuth Brandis², Madjid Samii', Marcos Tatagiba ${ }^{1}$
}

\begin{abstract}
A case of metastasis of breast adenocarcinoma into the internal auditory canal (IAC) and cerebellopontine angle (CPA) is presented, which appeared 16 years after primary tumor had been treated by surgery and radiation therapy. The 66-year old patient was considered cured from the primary disease, when she started with a rapidly developing hearing loss and intermittent facial palsy. Magnetic resonance image (MRI) displayed an intra- and extracanalicular tumor mass, which radiologically resembled a vestibular schwannoma. Surgery was performed and histopathological studies showed an adenocarcinoma compatible with breast origin. Metastasis is a rare occurrence within the IAC and CPA. Clinical history of severe facial palsy will rise suspicion of malignant tumor in spite of the radiological findings.
\end{abstract}

KEY WORDS: adenocarcinoma, breast cancer, cerebello-pontine angle, internal auditory canal, metastasis.

\begin{abstract}
Metástase tardia de adenocarcinoma de mama para o canal auditivo interno e ângulo ponto-cerebelar: relato de caso

RESUMO - Um caso de metástase de adenocarcinoma de mama para o canal auditivo interno e ângulo pontocerebelar é apresentado. A metástase ocorreu após 16 anos do tumor primário ter sido tratado com cirurgia e radioterapia. A paciente de 66 anos foi considerada curada de sua doença primária, quando apresentou perda auditiva de progressão rápida associada a paralisia facial intermitente. Ressonância magnética demonstrou uma lesão expansiva intra e extracanalicular, cujo aspecto radiológico lembrava schwannoma do vestibular. A paciente foi submetida a cirurgia e investigação histopatológica confirmou tratar-se de metástase. Metástase é uma rara ocorrência dentro do canal auditivo interno e ângulo ponto-cerebelar. História clínica de paralisia facial severa aumentará a suspeita de lesão maligna apesar dos achados radiológicos.
\end{abstract}

PALAVRAS-CHAVE: adenocarcinoma, ângulo ponto-cerebelar, canal auditivo interno, metástase, tumor de mama.

The most common lesion of internal auditory canal (IAC) and cerebellopontine angle (CPA) is vestibular schwannoma, which represents 91 per cent of all cases $^{1}$. Other lesions at this site include meningioma, epidermoid cyst, schwannoma of facial nerve, secondary cholesteatoma, lipoma, angioma and cysts. Malignant tumor account for less than one per cent of all lesions.

We describe a rare case of a metastasis of a breast cancer within the IAC, which resembled radiologically a vestibular schwannoma. The tumor appeared 16 years after primary tumor had been treated successfully without signs of recurrence hitherto.

\section{CASE}

A 66-year-old woman presented with intermittent leftsided facial paresis, tinitus and hearing loss of one and half year duration. At this time magnetic resonance imaging (MRI) showed a tiny hyperintense lesion just at the fundus of the internal auditory canal which was thought to be neuritis of the cranial nerves VII-VIII. At that time surgical treatment was not recommended, and the patient was followed up. Because symptoms became worse with severe facial palsy another MRI was done less than one year later, which showed a significant tumor progression. At the time of admission in our Department the patient had a complete facial palsy along with severe hearing loss and tinnitus on the left side. Clinical history was

\footnotetext{
'Department of Neurosurgery and 'Institute of Neuropathology, Hannover Medical School, Hannover, Germany.

Received 5 December 2001, received in final form 1 March 2002. Accepted 7 March 2002.

MD Dr. Marcos Tatagiba - Department of Neurosurgery - Hannover Medical School, Carl-Neuberg-Str. 1 - D- 30625 Hannover - Germany. E-mail: tatagiba.marcos@mh-hannover.de
} 

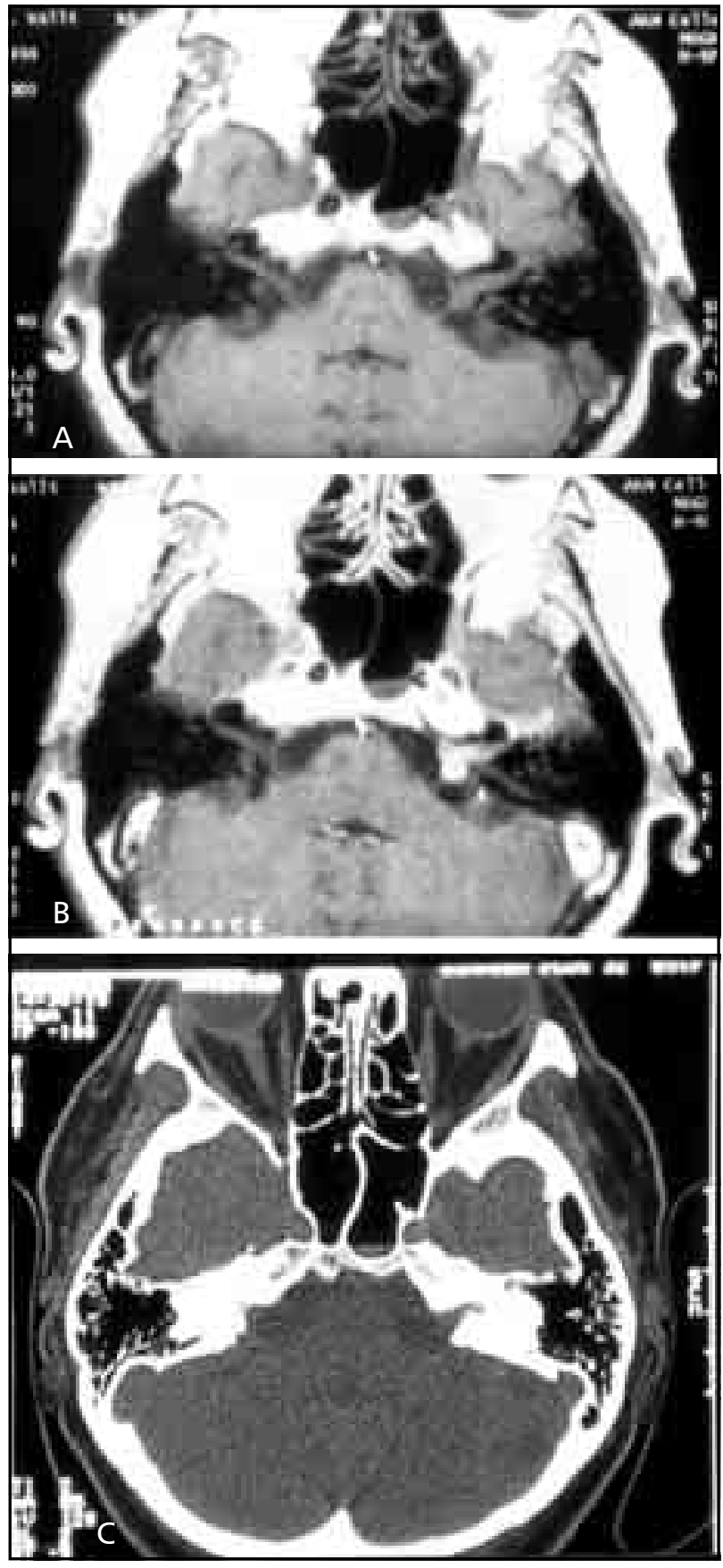

Fig 1. Axial MRI (T1) of posterior fossa at level of IAC shows an isointense $(A)$ left-sided tumor extending from the IAC to the CPA. $(B)$ the mass shows marked enhancement after contrast injection. (C) Slight widening of IAC is seen at bone window CT scan.

uneventful with exception of an adenocarcinoma of the left breast, which had been submitted to surgery and radiotherapy 16 years before. During the last 16 years the patient remained under clinical control investigations, and there had been no signs of tumor recurrence so far. Homogeneous contrast enhancement of the tumor, localization within the IAC and CPA, and lack of extra-nodular enhancement indicated radiologically a vestibular schwannoma as first suspicion (Fig 1). However, clinical
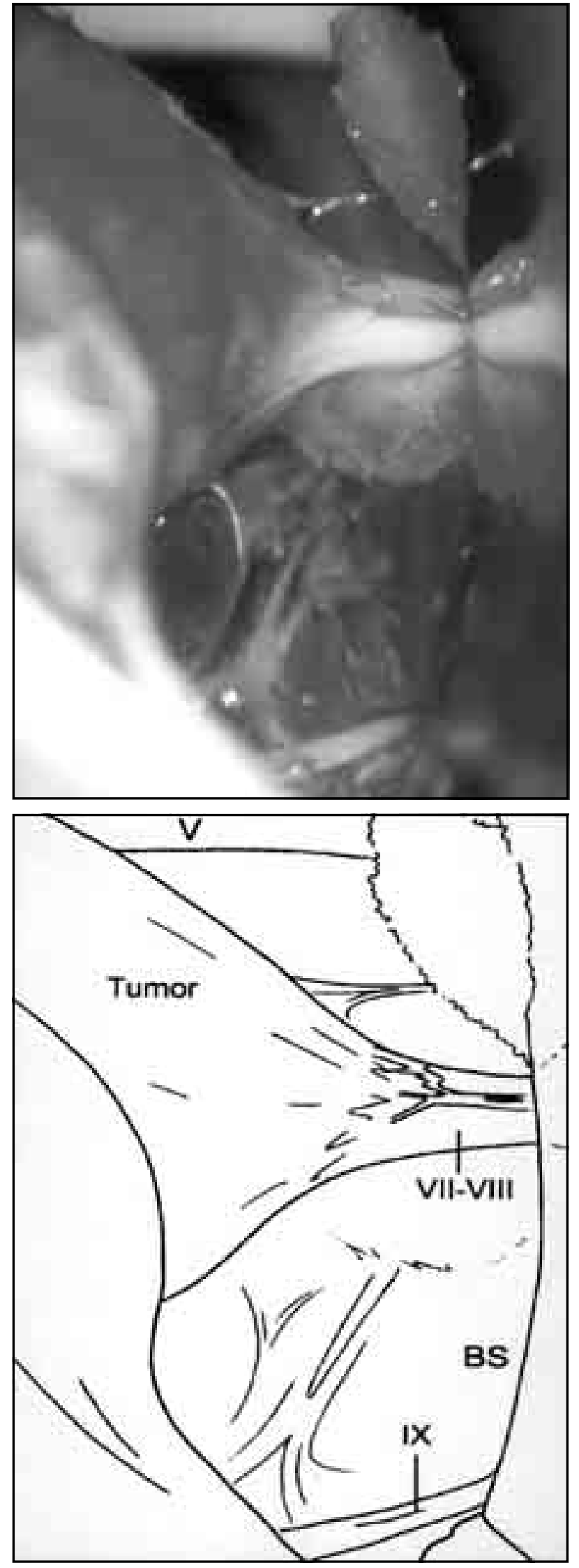

Fig 2. Intraoperative photograph of the CPA (sitting position) and drawing showing the tumor and the affected cranial nerves VII and VIII. $B S$ : brain stem; Roman numerals correspond to respective cranial nerves. 
history of severe facial palsy arose suspicion of a different lesion. Tumor exposure and resection was performed by a retrosigmoid transmeatal approach (MT). Cranial nerves VII and VIII were found completely infiltrated by tumor and had to be sacrificed to achieve a radical tumor removal (Fig 2). Postoperative evolution was uneventful with the patient maintaining her facial palsy and hearing loss on the left. Histopathological studies showed an adenocarcinoma compatible with breast origin, with infiltration of cranial nerves. Postoperative treatment included radiotherapy. Three months after surgery, MRI control showed no signs of tumor remnants at the IAC or CPA. Facial palsy was then treated with a hypoglossal-facial anastomosis, which was well tolerated by the patient.

\section{DISCUSSION}

Tinnitus, dizziness, and one sided hearing loss are the most common symptoms of vestibular schwannomas (VSs). This is the most frequent lesion of the IAC and CPA, accounting for more than $90 \%$ of all lesions ${ }^{1}$. Primary severe involvement of facial nerve is rare in VSs and appears specially in late stage. When it occurs intracanalicular lesions other than VSs must be suspected. Different diagnosis includes facial nerve schwannoma, meningioma, vascular lesion (cavernoma, hemangioblastoma, arteriovenous malformation), secondary cholesteatoma, subarachnoid cyst, chordoma, choroid plexus papiloma, lipoma, hamartoma or metastatic carcinomas ${ }^{1-5}$.

Metastasis is rare in IAC, representing $0.3 \%$ of CPA lesions ${ }^{1}$. To the temporal bone in general the exact incidence of metastatic lesions is unknown ${ }^{6,7}$. Metastasis at temporal bone may stay latent for long time before it becomes symptomatic. Even when it is confined to the IAC a metastasis may present asymptomatic ${ }^{6,7}$. More than 200 cases of metastasis to the temporal bone are described in the literature ${ }^{6-8}$. Primary metastasis to the IAC is very rare, however. The most common primary tumor in temporal bone metastasis is breast adenocarcinoma. Eighteen per cent of 103 reported cases of distant metastatic spread to the temporal bone reviewed by Hill and Kohut ${ }^{9}$ had breast as the primary site, followed by lung and kidney (respectively, $12 \%$ and $10 \%$ ). Cumberworth et al. ${ }^{6}$ reported one case of late metastasis from breast to external auditory canal and reviewed 165 case reports. Breast was the commonest primary site $(29 \%)$, followed by lung $(11 \%)$, prostate $(8 \%)$, unknown primary (8\%) and kidney (6\%). They found in literature 36 cases of metastasis of breast to the temporal bone. Gloria-Cruz et al. ${ }^{8}$ in a study of 415 temporal bones of 212 autopsies of patients with primary non-disseminated malignant neoplasms found 76 temporal bones with metastasis. Twentyone percent were originate from breast $(80 \%$ adenocarcinoma), $13 \%$ from lung and $11 \%$ from prostate. The review of 139 cases plus two cases reported by Streitmann and Sismanis revealed that almost $25 \%$ of all metastatic temporal bones had the breast as the primary tumor?

The most common site of metastasis in the temporal bone is the petrous apex. The involvement of internal auditory canal varies from $14 \%$ to $21 \%{ }^{7-10}$.

The way of spread, other than contiguous, occurs in two distinct modes: (1) vascular-osseous and (2) perineural/cerebrospinal fluid ${ }^{11}$. The vascular-osseous mode is the most common form and is found by the petrous apex, mastoid, middle ear and external canal involvement. Otherwise, perineural spread occurs by involvement of nerves in IAC and of labyrinthine endorgans through dissemination of tumor cells in the subarachnoid space. This dissemination explains a higher possibility of bilateral implantation as well the involvement of others nerves for this type of lesion ${ }^{7,12}$. In the present case, the infiltration of osseous and membranous labyrinth did not occur. This is in according to the findings made by GloriaCruz et al. ${ }^{8}$ that showed such infiltration to be infrequent.

Metastasis to the IAC and CPA is frequently marked by acute and rapidly progressive symptoms related to the seventh and/or eighth cranial nerves. Facial disorders were present in $74 \%$ of the cases with lesion in IAC reported by Streitmann and Sismanis ${ }^{7}$. Most of them were progressive. Yuh et al. ${ }^{12}$ by investigation of metastasis to CPA identified that in $92.2 \%$ at least one of these nerves were affected. They also found that the MRI findings were more extensive that suggested by clinical presentation. This lesion involves frequently other cranial nerves and can be bilateral.

The treatment of patients with small lesions in the internal auditory canal sometimes is conservative. This management is made when schwannoma is considered. By small lesions it is important a definition of type of lesion to a better approach to the patient. Metastasis must have an aggressive treatment and it must be dealt as soon as possible to enhance prognosis.

Exact identification of lesion type by imaging studies is difficult. Krainik et al. ${ }^{13}$ compared radiological features of six cases of CPA lesions other than schwannoma (one of them metastasis) with features 
of 20 vestibular schwannomas. The authors noted that at least one of following three features was found in unusual lesions of IAC: high signal on T1-weighted images, heterogeneous contrast enhancement, or extranodular contrast enhancement. They point out, however, that absence of these findings in CPA lesions does not exclude malignancy.

Clinical history is crucial and can lead to diagnosis. Once supposed malignancy, the adequate treatment, which consists in a multidisciplinary approach with surgery, radiotherapy and chemotherapy, should be promoted.

In conclusion, although metastasis is a rare event in CPA, attention must be paid for its occurrence. Clinical presentation with facial nerve palsy, and prior tumor location from breast, lung, prostate or kidney may rise suspicion of malignancy. Diagnosis of malignancy should relay primarily on clinical signs rather than on imaging features. Conservative management is not indicated when there is a suspicious of malignant lesion.

\section{REFERENCES}

1. Brackmann DE, Bartels LJ. Rare tumors of the cerebello-pontine angle. Otolaryngol Head Neck Surg 1980;88:555-559.

2. Ajal M, Roche J, Turner J, Fagan P. Unusual lesions of the internal auditory canal. J Laryngol Otol 1998;112:650-653.

3. Babin RW, Fratkin JD, Cancilla PA. Hamartomas of the cerebellopontine angle and internal auditory canal. Arch Otolaryngol 1980;106:500-502.

4. Kinney WC, Kinney SM, Perl II J, Chyatte D, Miller DW, Payson RA. Rare lesions of the posterior fossa with initial retrocochlear auditory and vestibular complaints. Am J Otol 1997;18:373-380.

5. Kohan D, Downey LL, Lim J, Cohen NL, Elowitz E. Uncommon lesions presenting as tumours of the internal auditory canal and cerebellopontine angle. Am J Otol 1997;18:386-392.

6. Cumberworth VL, Friedmann I, Glover GW. Late metastasis of breast carcinoma to the external auditory canal. J Laryngol Otol 1994;108:808-810.

7. Streitmann MJ, Sismanis A. Metastatic carcinoma of the temporal bone. Am J Otol 1996;17:780-783.

8. Gloria-Cruz TI, Schachern PA, Paparella MM, Adams GL, Fulton SE Metastases to temporal bones from primary nonsystematic malignant neoplasms. Arch Otolaryngol Head Neck Surg 2000;126:209-214.

9. Hill BA, Kohut RI. Metastatic adenocarcinoma of the temporal bone. Arch Otolaryngol 1976;102:568-571.

10. Belal A Jr. Metastatic tumours of the temporal bone - a histopathological report. J Laryngol Otol 1985;99:839-846.

11. Jahn AF, Farkashidy J, Berman JM. Metastatic tumors in the temporal bone: a pathophysiologic study. J Otolaryngol 1979;8:85-95.

12. Yuh WT, Mayr-Yuh NA, Koci TM, et al. Metastatic lesions involving the cerebellopontine angle. Am J Neuroradiol 1993;14:99-106.

13. Krainik A, Cyna-Gorse F, Bouccara D, et al. MRI of unusual lesions in the internal auditory canal. Neuroradiology 2001;43:52-57. 